\title{
Author Correction: Clonal hematopoiesis in patients with rheumatoid arthritis
}

Paula Savola, Sofie Lundgren, Mikko A. I. Keränen, Henrikki Almusa, Pekka Ellonen, Marjatta Leirisalo-Repo,

Tiina Kelkka and Satu Mustjoki

Correction to: Blood Cancer Journal

https://doi.org/10.1038/s41408-018-0107-2

published online 26 July 2018

We detected unintentional small errors in three columns in Table 1 of the published version of the article, which were due to copy-paste errors in the final phase of preparing the table for the submitted manuscript. Errors do not anyhow change the manuscript text or message; only patient age and smoking status were incorrect for some patients.

We apologize for the errors and for the inconvenience this causes, and we ask for a corrigendum for Table 1. We also reviewed the other figures and tables of the manuscript, and these do not include erroneous information.

Published online: 17 February 2021 


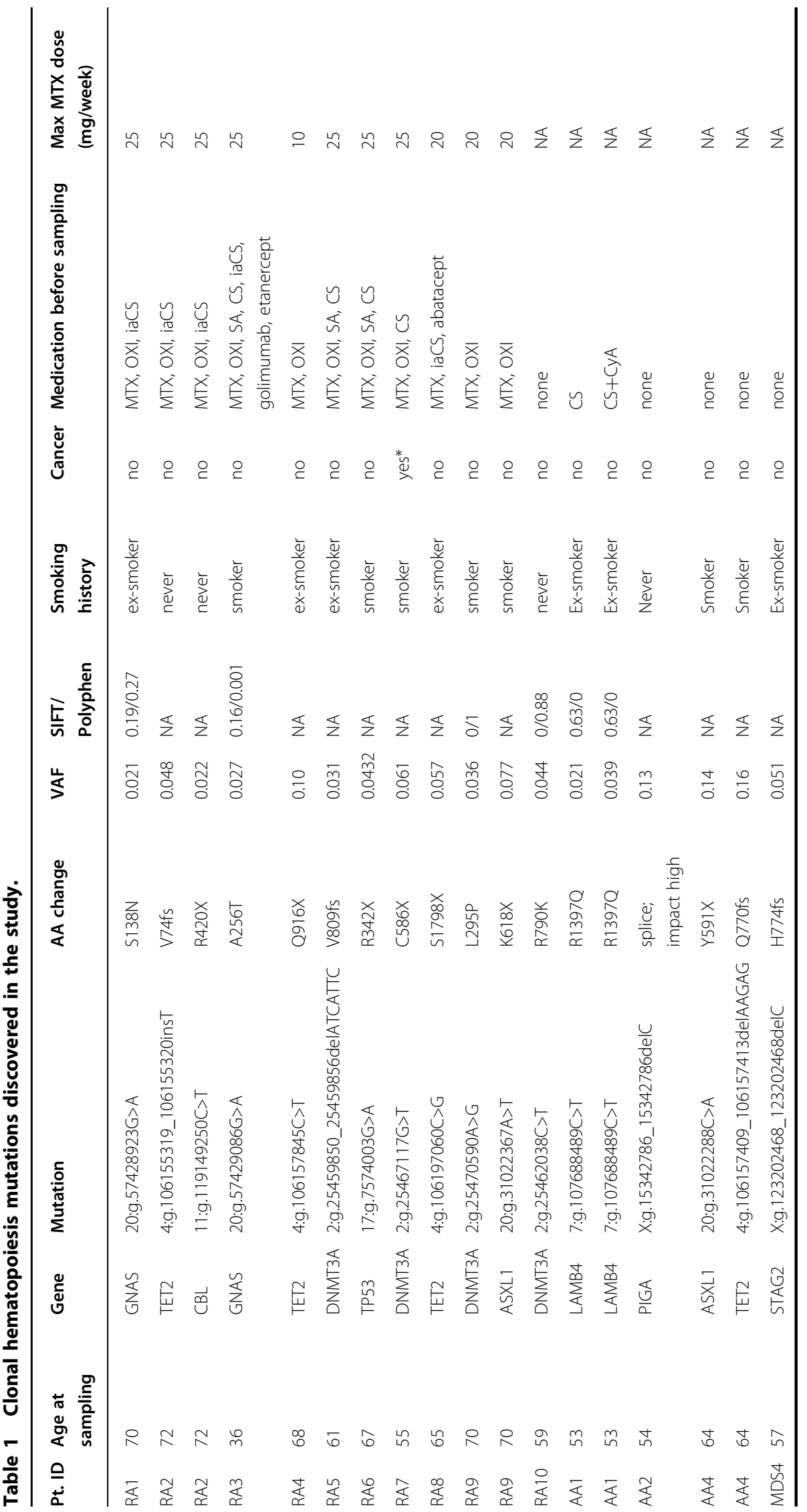

